\title{
Health risk behaviours among adolescents in Argentina: trends between 2007, 2012 and 2018 national cross-sectional school surveys
}

Karl Peltzer ${ }^{1,2}$ and Supa Pengpid ${ }^{2,3^{*}}$

\begin{abstract}
Background: The aim of this study was to assess trends of various health risk behaviours among adolescents across three different surveys in Argentina.

Methods: Data from 115,697 adolescents (mean age:14.6 years, SD $=1.2$ ) that participated in three cross-sectional national school surveys in 2007, 2012 and 2018 were analysed. In all, 27 health risk behaviours were assessed through a self-administered questionnaire. Significance of a linear trend was tested by treating study year as categorical variable in logistic regression analyses, adjusted by age group and food insecurity for boys and girls separately

Results: Among both sexes, four health risk behaviours (current cigarette use, passive smoking, trouble from alcohol use, and physically attacked) significantly reduced from 2007 to 2018. Among boys five health risk behaviours (experience of hunger, parental tobacco use, current alcohol use, involvement in physical fighting, and multiple sexual partners), and among girls, inadequate physical activity significantly reduced over time. Among both sexes, the prevalence of four health risk behaviours (overweight/obesity, obesity, leisure-time sedentary behaviour and insufficient fruit intake) significantly increased among both sexes, and among girls ten health risk behaviours (not walking/biking to school, current other tobacco use, bullying victimisation, lifetime drunkenness, having no close friends, suicide plan, suicidal ideation, worry-induced sleep disturbance, loneliness, and ever sexual intercourse) significantly increased over time.
\end{abstract}

Conclusion: Nine health risk behaviours among boys and five health risk behaviours among girls decreased, and four health risk behaviours among boys and 14 health compromising behaviours among girls increased over a period of 11 years. School health programmes for adolescents should be strengthened in Argentina.

Keywords: substance use, physical activity, diet, sexual behaviour, injury, mental health, violence, Argentina

*Correspondence: supa.pen@mahidol.ac.th

${ }^{3}$ ASEAN Institute for Health Development, Mahidol University, Salaya,

Phutthamonthon, Nakhon Pathom, Thailand

Full list of author information is available at the end of the article

\section{Background}

In Southern Cone States (Uruguay, Paraguay, Chile, Brazil, and Argentina), most death (75.3\%) is caused by non-communicable diseases (NCDs), and in Argentina, an upper middle-income country, $78 \%$ of death is caused by NCDs [1]. There has been an increase of NCDs and its risk factors in Latin America, including in Argentina $[1,2]$. In Southern Cone States, the prevalence of 
behavioural NCD risk factors in 2016 was $23.5 \%$ for adult obesity and $10.2 \%$ for adolescent obesity (Argentina $28.3 \%$ adult and $14.4 \%$ in adolescent obesity), $17.2 \%$ and $10.8 \%$ for current tobacco smoking among adults and adolescents, respectively (Argentina 21.9\% and 20.2\% for current tobacco smoking among adults and adolescents, respectively), and $44.3 \%$ for adult physical inactivity (Argentina 41.6\%) [1]. In a survey among adults in primary care in Central Argentina, the prevalence of inadequate fruit and vegetable intake was $91.8 \%$, physical inactivity $71.5 \%$, dyslipidaemia $43.5 \%$, obesity $35.2 \%$, hazardous alcohol use 28\%, and smoking 22.5\% [3]. Generally, among adults in Argentina there has an increase of poor diet, physical inactivity, obesity, diabetes, and dyslipidaemia, but a decrease in tobacco use [4]. It is estimated that among young people and adults globally, "alcohol use, dietary behaviours, drug use, mental health, physical activity, sexual behaviours, tobacco use, violence and unintentional injury" are leading causes of morbidity and mortality [5].

In 26 countries in Latin America and the Caribbean 84.5\% of adolescents (83.3\% in Argentina in 2012) were not physically active [6], and in 12 countries $50 \%$ and more adolescents reported sedentary behaviour (50.8 sedentary in Argentina in 2012) [6]. The prevalence of past 12-month physical injury was in 2012-2013, for example 27.1\% in Argentina and 29.5\% in Uruguay [7]. In a sample of adolescents in Argentina, 6\% were traditional bullies [8], and in a national sample of school adolescents in Argentina, the prevalence of past-month bullying victimization was $24.4 \%$ [9]. Comparing 13-15 year-old school adolescent from the Argentina 2007 and 2012 Global School-based Student Health Survey (GSHS) and Global Youth Tobacco Survey, found a prevalence of overweight (24.5\%) and obesity (4.4\%) in 2007 and $28.6 \%$ and $5.9 \%$, respectively in 2012 , and the prevalence of insufficient vegetable and fruit consumption was $86.0 \%$ in 2007 and $82.4 \%$ in 2012 , physical inactivity $87.3 \%$ in 2007 and $83.3 \%$ in 2012 , sedentary behaviour $49.2 \%$ in 2007 and $50.3 \%$ in 2012, current smokers $24.5 \%$ in 2007 and $19.6 \%$ in 2012, and exposure to passive smoking at home $54.7 \%$ in 2007 and $44.5 \%$ in 2012 [10]. In 21 Latin American and Caribbean Countries, the prevalence of suicidal ideation with planning was $7.5 \%$ and $17.5 \%$, among male and female adolescents, respectively, loneliness $10.0 \%$ in Argentina in 2012, no close friends 5.3\% in Argentina in 2012, and food insecurity $3.8 \%$ in Argentina in 2012 [11]. In a study among school adolescents in 25 countries in Latin America and the Caribbean 18.1\% reported loneliness and/or having no close friends [12]. The prevalence of current alcohol among 13-15-year-olds in Argentina in 2007 was 51.9\% [13], and among adolescents from eight countries in
South America and the Caribbean, 18.4\% had suicidal ideation, $8.7 \%$ anxiety, $15.0 \%$ multiple sexual partners and $33.8 \%$ school truancy [14]. Among national school adolescent surveys in Bolivia, Costa Rica, Honduras, Peru, and Uruguay, 33.2\% had been involved in physical fighting, $37.8 \%$ were bullied and $6.7 \%$ had not used a condom at last sex [15], while in a large national study among adolescents in Brazil, 30.8\% had not used a condom at last sex, and more than $63 \%$ had multiple sexual partners ( $>63 \%)$ in Brazil [16]. In terms of protective factors, among adolescents in five Caribbean countries, the prevalence of parental supervision was $38.2 \%$, parental connectedness $32.9 \%$ and parental bonding $40.2 \%$ [17].

The prevalence of health risk behaviours in adolescents need to be monitored over time at country level to make intervention strategies more appropriate and successful $[18,19]$. For example, in a trend study among school-going adolescents in Morocco from 2006 to 2016, "five health risk behaviours (being physically attacked, annual injury, passive smoking, zero days walking or biking to school, and poor hand hygiene after toilet use) significantly declined over time, and inadequate fruit intake and current tobacco use increased over time." [20]. No trend study among adolescents on various health risk behaviours has been identified in Latin America, including Argentina. Therefore, the aim of this study was assessing trends of 27 health risk behaviours in the 2007, 2012 and 2018 Argentina GSHS. Findings from such a trend study on the epidemiology of health compromising behaviours may help us to understand and design better school health promotion strategies [20].

\section{Methods}

\section{Sample and procedure}

Data from 115,697 adolescents (mean age:14.6 years, $\mathrm{SD}=1.2$ ) that participated in three cross-sectional national school surveys in 2007, 2012 and 2018 in Argentina were analysed [5]. For the 2007 Argentina GSHS the response rate was $77 \%$, for the 2012 Argentina GSHS 71\% and for the 2018 Argentina GSHS 63\% [5]. Details of the GSHS and the dataset can be accessed [5]. Briefly, "using a two-stage cluster sampling strategy (schools were selected by probability to size sampling and random selection of classrooms with students 13 to 17 years of age), nationally representative samples of middle school students were produced." [5] "All students who attended a selected class were eligible to participate, regardless of their age, and completed a self-administered questionnaire in their language under the supervision of trained external survey administrators." [5] The study was granted ethics approval by a national ethics committee and written informed consent was obtained from the participants or their guardians before the survey [5]. 


\section{Measures}

All health risk behaviours of the GSHS measure [5] that were administered in the 2007, 2012 and 2018 Argentina GSHS were included in this study (see Table 1). This included body weight and dietary behaviour (overweight or obesity, obesity, food insecurity or hunger, and vegetable and fruit intake), leisure-time sedentary behaviour, walking or biking to school, and physical activity, substance use (parental tobacco use, current cigarette use, current other tobacco use, passive smoking, current alcohol use, drunkenness, trouble as a result of drinking alcohol), injury and violence (bullied, attacked, and in a physical fight), psychological health (having friends, loneliness, worry-induced sleep problems, suicide plan, and suicidal ideation), and sexual behaviour (ever sexual intercourse, multiple sexual partners, and non-condom use). In addition, protective measures included peer support, school attendance, and parental support. The intake of "less than two or more servings of fruits in a day" and "less than three or more servings of vegetables a day" were classified as inadequate [21]. "Inadequate physical activity was defined as not daily at least 60 minutes of moderate to vigorous-intensity physical activity." [22]. "Leisure-time sedentary behaviour was defined as spending three or more hours per day sitting." [23].

\section{Data analysis}

Cross-sectional national datasets from three Argentina GSHS in 2007, 2012 and 2018 were merged, and weighted for probability selected and non-response. Chi-square tests were utilized for analysing differences in proportions, and descriptive health risk behaviour information was reported as percentages for each study year. The significance of linear trends was analysed by using study year as categorical variable in logistic regression analyses, adjusted by age group and food insecurity for boys and girls separately. Taylor linearization methods were used in statistical analyses accounting for sample weight and multi-stage sampling. Missing data were excluded from the analyses, and $p<0.05$ was accepted as significant. All statistical analyses were done using STATA software version 15.0 (Stata Corporation, College Station, Texas, USA).

\section{Results}

\section{Sample characteristics}

The total sample included 115,697 adolescents (Mean age: 14.6 years, $\mathrm{SD}=1.2$ ), and $51.9 \%$ were females. Compared to the first two surveys, the students attending '2nd year/11th grade polymodal or 4th year of high school' or '3rd year/12nd grade polymodal or 5th year of high school' were included in the third survey $(p<0.001)$ (see Table 2).

\section{Outcome variables}

\section{Body weight and dietary behaviour}

The prevalence of overweight or obesity was $21.5 \%$ among boys and $12.4 \%$ among girls in 2007, which significantly increased to $35.2 \%$ among boys and $25.9 \%$ among girls in 2018. Similarly, the proportion of obesity increased among both boys and girls from 2007 (3.0\% and $1.9 \%$, respectively) to 2018 (9.7\% and $5.2 \%$, respectively). The prevalence of inadequate fruit consumption increased from $70.6 \%$ to $79.6 \%$ among boys and from $65.4 \%$ to $78.6 \%$ among girls from 2007 to 2018 , while the prevalence of inadequate vegetable intake did not significantly change among both boys and girls over time. Experiencing hunger was low and decreased significantly in boys from $4.3 \%$ in 2007 to $2.3 \%$ in 2018 but did not change among girls over time.

\section{Physical activity and sedentary behaviour}

Both male and female adolescents reported a high prevalence of physical inactivity (boys: $82.7 \%$ and girls: $92.2 \%$ ), which decreased significantly among girls (87.1\%) and remained unchanged among boys (79.6\%) over time. Leisure-time sedentary behaviour significantly increased among both boys from $44.7 \%$ in 2007 to $52.8 \%$ in 2018 and girls from $51.0 \%$ in 2007 to $57.7 \%$ in 2018 . Not walking/biking to school significantly increased from $26.2 \%$ in 2007 to $34.0 \%$ in 2018 among girls but remained unchanged among boys.

\section{Substance use}

Among both boys and girls, parental tobacco use decreased over time from $38.4 \%$ to $33.8 \%$ among boys and $38.6 \%$ to $35.2 \%$ among girls. The prevalence of current cigarette use, significantly decreased from $24.3 \%$ in 2007 to $17.2 \%$ in 2018 among boys and from $26.9 \%$ in 2007 to $20.6 \%$ in 2018 among girls. However, among girls, current other tobacco use, almost doubled from $4.3 \%$ in 2007 to $8.0 \%$ in 2018 , while among boys, current other tobacco use remained unchanged. The proportion of passive smoking reduced significantly among both boys and girls over time. Current alcohol use, significantly declined among boys but not among girls over time. Trouble from alcohol use decreased significantly among both boys and girls from 2007 to 2018, while lifetime drunkenness significantly increased among girls from $31.2 \%$ in 2007 to $38.8 \%$ in 2018 and remained unchanged among boys.

\section{Violence and injury}

The proportion of injury did not change significantly among boys and girls from 2007 to 2018. Bullying victimisation increased in both boys and girls, but only in girls significantly from $23.6 \%$ in 2007 to $34.9 \%$ in 2018 . Being physical assaulted reduced in both sexes over time 
Table 1 Description of study variables.

\begin{tabular}{l} 
Variables \\
\hline Age \\
Sex \\
Grade \\
Food insecurity \\
Body weight and dietary behaviour \\
Height \\
Weight \\
Fruits
\end{tabular}

Vegetables

Hunger

\section{Physical activity and sedentary behaviour}

"Physical activity"

"Leisure-time sedentary behaviour"

"Walking or biking to school"

\section{Substance use}

"Parental tobacco use"

"Current smoking cigarettes"

"Current other tobacco use"

"Passive smoking"

"Current alcohol use"

"Drunk"

"Trouble from alcohol use"

\section{Injury and violence}

"Injury"

\section{Question}

"How old are you?"

"What is your sex?"

"In what grade/class/standard are you?"

"During the past 30 days, how often did you go hungry because there was not enough food in your home?"

"How tall are you without your shoes on?" "How much do you weigh without your shoes on?" "During the past 30 days, how many times per day did you usually (past 7 days how many times did you) eat fruit such as apples, bananas, or mandarins?"

"During the past 30 days/7 days, how many times per day did you usually (past 7 days how many times did you) eat vegetables, such as lettuce, tomatoes, carrots, or pumpkin?"

"During the past 30 days, how often did you go hungry because there was not enough food in your home?"

"Physical activity is any activity that increases your heart rate and makes you get out of breath some of the time. Physical activity can be done in sports, playing with friends, or walking to school. Some examples of physical activity are running, fast walking, biking, dancing, football, swimming, or skating." "During the past 7 days, on how many days were you physically active for a total of at least 60 minutes per day?"

"How much time do you spend during a typical or usual day sitting and watching television, playing computer games, talking with friends, or doing other sitting activities, such as using the computer or cell phone?"

"During the past 7 days, on how many days did you walk or ride a bicycle to or from school?"

"Which of your parents or guardians use any form of tobacco?"

"During the past 30 days, on how many days did you smoke cigarettes?"

"During the past 30 days, on how many days did you use any tobacco products other than cigarettes, such as pipes, narguile, or smokeless tobacco?"

"During the past 7 days, on how many days have people smoked in your presence?"

"During the past 30 days, on how many days did you have at least one drink containing alcohol?"

"During your life, how many times did you drink so much alcohol that you were really drunk?"

"During your life, how many times have you got into trouble with your family or friends, missed school, or got into fights, as a result of drinking alcohol?"

"During the past 12 months, how many times were you seriously injured?"

\section{Response options (coding scheme)}

"11 years old or younger to 16 or 18 years old or older" "Male, Female"

" $1=$ never to $5=$ always"

"(coded $1=0,2-3=2$ and $4-5=1$ )"

$" 1=1$ did not eat fruit during the past 30 days $/ 7$ days to $7=5$ or more/4 or more times per day" "(coded $<2$ times/day)"

"I did not eat vegetables during the past 30 days to $7=5$ or more $/ 4$ or more times per day" "(coded <3 times/day"

" $1=$ never to $5=$ always"

"(coded $1-3=0$ and $4-5=1)$ "

" $0=0$ days to $7=7$ days"

"(coded $0-6=0$ and $7=1$ )"

" $1=$ less than 1 hour per day; $2=1-2$ hrs $/$ day; $3=3-4$ hrs/ day; $4=5-6 \mathrm{hrs} /$ day; $5=7-8 \mathrm{hrs} /$ day and $6=8$ or more hours per day"

" $1=0$ days to $8=7$ days"

"(coded $1=1$ and $2-8=0$ )"

"Neither, My father or male guardian, My mother or female guardian, Both"

"(coded $0=$ neither and $1=$ either)"

$" 1=0$ days to $7=$ All 30 days" $"($ coded $1=0$ and $2-7=1$ )"

$" 1=0$ days to $7=$ All 30 days" (coded $1=0$ and $2-7=1$ )"

$" 1=0$ days to $5=$ all 7 days" $($ coded $1=0$ and $2-5=1) "$

$" 1=0$ days to $7=$ All 30 days" (coded $1=0$ and $2-7=1$ )"

$" 1=0$ times to $4=10$ or more times" $($ coded $1=2=4$ and $0=1)^{\prime \prime}$

$" 1=0$ times to $4=10$ or more times" $($ coded $1=2=4$ and $0=1)^{\prime \prime}$

" $1=0$ times to $8=12$ or more times" (coded $1=0$ and $2-8=1)^{\prime \prime}$ 
Table 1 (continued)

\begin{tabular}{|c|c|c|}
\hline Variables & Question & Response options (coding scheme) \\
\hline "Bullied" & $\begin{array}{l}\text { "Bullying occurs when one or more students or } \\
\text { someone else about your age teases, threatens, } \\
\text { ignores, spreads rumors about, hits, shoves, or hurts } \\
\text { another person over and over again. It is not bullying } \\
\text { when two people of about the same strength or } \\
\text { power argue or fight or tease each other in a friendly } \\
\text { way?" } \\
\text { GSHS } 2007 \text { and } 2012 \\
\text { "During the past } 30 \text { days, on how many days were } \\
\text { you bullied?" } \\
\text { GSHS } 2018 \\
\text { "During the past } 12 \text { months, have you ever been bul- } \\
\text { lied on school property?" } \\
\text { "During the past } 12 \text { months, have you ever been bul- } \\
\text { lied when you were not on school property?" }\end{array}$ & $\begin{array}{l}\text { " } 1=0 \text { days to } 7=\text { All } 30 \text { days" }(\text { coded } 1=0 \text { and } 2-7=1) " \\
\text { "Yes, No" } \\
\text { "Yes, No" } \\
\text { (coded any of the two }=1 \text { ) }\end{array}$ \\
\hline "In a physical fight" & $\begin{array}{l}\text { "During the past } 12 \text { months, how many times were } \\
\text { you in a physical fight?" }\end{array}$ & $\begin{array}{l}" 1=0 \text { times to } 8=12 \text { or more times (coded } 1=0 \text { and } \\
2-8=1 \text { )" }\end{array}$ \\
\hline "Physically attacked" & $\begin{array}{l}\text { "During the past } 12 \text { months, how many times were } \\
\text { you physically attacked?" }\end{array}$ & $\begin{array}{l}\text { " } 1=0 \text { times to } 8=12 \text { or more times (coded } 1=0 \text { and } \\
2-8=1 \text { )" }\end{array}$ \\
\hline \multicolumn{3}{|l|}{ Poor mental health } \\
\hline "No close friends" & "How many close friends do you have?" & $" 1=0$ to $4=3$ or more $($ coded $1+=0,0=1) "$ \\
\hline "Loneliness" & $\begin{array}{l}\text { "During the past } 12 \text { months, how often have you felt } \\
\text { lonely?" }\end{array}$ & $" 1=$ never to $5=$ always $($ coded $1-3=0$ and $4-5=1) "$ \\
\hline "Worry-induced sleep disturbance" & $\begin{array}{l}\text { "During the past } 12 \text { months, how often have you } \\
\text { been so worried about something that you could not } \\
\text { sleep at night?" }\end{array}$ & $" 1=$ never to $5=$ always $($ coded $1-3=0$ and $4-5=1) "$ \\
\hline "Suicidal ideation" & $\begin{array}{l}\text { "During the past } 12 \text { months, did you ever seriously } \\
\text { consider attempting suicide?" }\end{array}$ & "Yes, No" \\
\hline "Suicide plan" & $\begin{array}{l}\text { "During the past } 12 \text { months, did you make a plan } \\
\text { about how you would attempt suicide?" }\end{array}$ & "Yes, No" \\
\hline \multicolumn{3}{|l|}{ Sexual behaviour } \\
\hline "Ever had sex" & "Have you ever had sexual intercourse?" & "Yes, No" \\
\hline "Multiple sexual partners" & $\begin{array}{l}\text { "During your life, with how many people have you } \\
\text { had sexual intercourse?" }\end{array}$ & $\begin{array}{l}\text { " } 1=\text { never had sex to } 7=6 \text { or more people (coded } \\
1=3-7 \text { and } 0=1-2 \text { )" }\end{array}$ \\
\hline "Non-condom use" & $\begin{array}{l}\text { "The last time you had sexual intercourse, did you } \\
\text { or your partner use a condom, forro, preservativo, or } \\
\text { profilactico?" }\end{array}$ & $\begin{array}{l}\text { "Never had sex/Yes/No (coded } 1=\text { No and } 0=\text { never had } \\
\text { sex/yes)" }\end{array}$ \\
\hline \multicolumn{3}{|l|}{ Protective factors } \\
\hline "School attendance" & $\begin{array}{l}\text { "During the past } 30 \text { days, on how many days did you } \\
\text { miss classes or school without permission?" }\end{array}$ & $\begin{array}{l}" 1=0 \text { days to } 5=10 \text { or more days (coded } 1=1 \text { and } \\
2-5=0) "\end{array}$ \\
\hline "Peer support" & $\begin{array}{l}\text { "During the past } 30 \text { days, how often were most of the } \\
\text { students in your school kind and helpful?" }\end{array}$ & $" 1=$ never to $5=$ always $($ coded $1-3=0$ and $4-5=1) "$ \\
\hline "Parental supervision" & $\begin{array}{l}\text { "During the past } 30 \text { days, how often did your parents } \\
\text { or } \\
\text { guardians check to see if your homework was done?" }\end{array}$ & $" 1=$ never to $5=$ always $($ coded $1-3=0$ and $4-5=1) "$ \\
\hline "Parental connectedness" & $\begin{array}{l}\text { "During the past } 30 \text { days, how often did your parents } \\
\text { or } \\
\text { guardians understand your problems and worries?" }\end{array}$ & $" 1=$ never to $5=$ always (coded $1-3=0$ and $4-5=1$ )" \\
\hline "Parental bonding" & $\begin{array}{l}\text { "During the past } 30 \text { days, how often did your parents } \\
\text { or guardians really know what you were doing with } \\
\text { your free time?" }\end{array}$ & $" 1=$ never to $5=$ always (coded $1-3=0$ and $4-5=1$ )" \\
\hline
\end{tabular}

from $30.2 \%$ to $19.3 \%$ among boys and from $19.2 \%$ to $15.9 \%$ among girls and participation in physical fighting decreased significantly among boys from $43.8 \%$ to $33.3 \%$ and reduced among girls from $19.6 \%$ to $16.5 \%$ but not significantly.

\section{Psychological health}

All five indicators ("having no close friends, worryinduced sleep disturbance, loneliness, suicidal ideation and suicide plan") significantly increased among girls but not among boys over time. 
Table 2 Characteristics of adolescent students for 2007, 2012 and 2018 surveys in Argentina

\begin{tabular}{|c|c|c|c|}
\hline \multirow[t]{2}{*}{ Variable } & $2007(N=1,980)$ & $2012(N=56,736)$ & $2018(N=56,981)$ \\
\hline & $N(\%)$ & $\mathrm{N}(\%)$ & $\mathrm{N}(\%)$ \\
\hline \multicolumn{4}{|l|}{ Sex } \\
\hline Male & $957(48.0)$ & $26728(48.3)$ & $27083(48.0)$ \\
\hline Female & $994(52.0)$ & $29248(51.7)$ & $29362(52.0)$ \\
\hline Missing & 29 & 760 & 536 \\
\hline \multicolumn{4}{|l|}{ Age in years } \\
\hline 13 years or younger & $370(18.7)$ & $11412(26.0)$ & $10767(21.0)$ \\
\hline 14 & $600(27.0)$ & $16354(29.5)$ & $12946(25.0)$ \\
\hline 15 & $576(29.6)$ & $15448(25.4)$ & $12812(22.0)$ \\
\hline 16 years or older & $400(24.8)$ & $12812(19.2)$ & $20348(31.9)$ \\
\hline Missing & 34 & 468 & 108 \\
\hline \multicolumn{4}{|l|}{ Grade } \\
\hline A & $732(38.4)$ & $28576(37.2)$ & $8581(14.7)$ \\
\hline B & $880(32.0)$ & $19944(33.5)$ & $11913(26.9)$ \\
\hline$C$ & $337(29.7)$ & $16574(29.3)$ & $12448(23.3)$ \\
\hline D-E & 0 & 0 & $22978(35.1)$ \\
\hline Missing & 31 & 1642 & 1061 \\
\hline \multicolumn{4}{|c|}{ Food insecurity (as proxy for socioeconomic status) } \\
\hline None & $1321(67.1)$ & $35222(64.4)$ & $38257(68.4)$ \\
\hline Moderate & $588(29.8)$ & $18680(31.7)$ & $17162(29.6)$ \\
\hline Severe & $58(3.1)$ & $2140(3.9)$ & $1063(2.0)$ \\
\hline Missing & 13 & 694 & 499 \\
\hline
\end{tabular}

$\mathrm{A}={ }^{\prime}$ '8th grade of primary school/polimodal or 1st year of high school'; $\mathrm{B}={ }^{\prime}$ '9th grade of primary school/polimodal or 2nd year of high school'; $\mathrm{C}==^{\prime} 1$ st year/10th grade polimodal or 3rd year of high school'; $\mathrm{D}=$ ='2nd year/11th grade polimodal or 4th year of high school'; $\mathrm{E}=$ '3rd year/12nd grade polimodal or 5th year of high school.'

\section{Sexual behaviour}

Ever having had sexual intercourse significantly increased among girls from $24.4 \%$ in 2007 to $36.4 \%$ in 2018 but remained unchanged among boys. The prevalence of having multiple sexual partners significantly reduced from $34.8 \%$ to $28.4 \%$ among boys but not among girls (from $13.6 \%$ to $16.9 \%$ ). The proportion of non-condom use at last sex remained unchanged among both boys and girls over time.

\section{Protective indicators}

School attendance in the past 30 days significantly increased among both boys and girls from 2007 to 2018. Peer support significantly decreased among girls but not boys over time. Parental supervision and connectedness decreased significantly among both boys and girls from 2007 to 2018, while parental bonding did not change over time (see Tables 3 and 4).

\section{Discussion}

Results show for the first time that across three GSHS in 2007, 2012 and 2018 in Argentina, among both sexes a significant decrease in the prevalence of current cigarette use, passive smoking, trouble from alcohol use, and physically attacked, and among boys, experience of hunger, parental tobacco use, current alcohol use, involvement in physical fighting, and multiple sexual partners, and among girls, inadequate physical inactivity. However, overweight/obesity, obesity, leisure-time sedentary behaviour and insufficient fruit intake significantly increased among both boys and girls, and among girls not walking/biking to school, current other tobacco use, bullying victimisation, lifetime drunkenness, having no close friends, loneliness, worry-induced sleep disturbance, suicidal ideation, suicide plan, and ever sexual intercourse significantly increased over time.

The significant reduction in current cigarette use, and passive smoking, also found in the Argentina Global Youth Tobacco Survey [10], may be attributed to the introduction of the smoke-free law in Argentina in 2011, including a "total ban on smoking in public settings, prohibition of advertising and promotional activities 
Table 3 Health risk behaviours among male adolescents in 2007, 2012 and 2018 in Argentina

\begin{tabular}{|c|c|c|c|c|c|}
\hline \multirow[t]{2}{*}{ Outcome variable } & \multirow{2}{*}{$\begin{array}{l}2007 \\
\%\end{array}$} & \multirow{2}{*}{$\begin{array}{l}2012 \\
\%\end{array}$} & \multirow{2}{*}{$\begin{array}{l}2018 \\
\%\end{array}$} & \multirow[t]{2}{*}{ Difference $^{a}$} & \multirow[t]{2}{*}{$\mathrm{p}$-for trend $\mathrm{b}^{\mathrm{b}}$} \\
\hline & & & & & \\
\hline \multicolumn{6}{|l|}{ Body weight and dietary behaviour } \\
\hline Overweight/obesity & 21.5 & 35.0 & 35.2 & +13.7 & $<0.001$ \\
\hline Obesity & 3.0 & 8.9 & 9.7 & +6.7 & $<0.001$ \\
\hline Fruits $<2$ times/day & 70.6 & 64.6 & 79.6 & +9.0 & $<0.001$ \\
\hline Vegetable $<3$ times/day & 92.3 & 87.6 & 89.9 & -2.4 & 0.076 \\
\hline Went hungry (mostly/always) & 4.3 & 4.6 & 2.3 & -2.0 & 0.013 \\
\hline \multicolumn{6}{|l|}{ Physical activity and sedentary behaviour } \\
\hline Physical inactivity & 82.7 & 78.1 & 79.6 & -3.1 & 0.220 \\
\hline Leisure-time sedentary behaviour & 44.7 & 46.9 & 52.8 & +8.1 & 0.003 \\
\hline 0 days walk or bike to school & 27.0 & 31.3 & 30.0 & +3.0 & 0.485 \\
\hline \multicolumn{6}{|l|}{ Substance use } \\
\hline Parental tobacco use & 38.4 & 37.6 & 33.8 & -4.6 & 0.036 \\
\hline Current cigarette use & 24.3 & 19.2 & 17.2 & -7.1 & $<0.001$ \\
\hline Current other tobacco use & 8.3 & 8.8 & 8.2 & -0.1 & 0.965 \\
\hline Passive smoking & 77.9 & 71.0 & 64.3 & -13.6 & $<0.001$ \\
\hline Current alcohol use & 61.5 & 52.0 & 52.4 & -9.1 & 0.008 \\
\hline Lifetime drunk & 38.7 & 32.8 & 35.7 & -3.0 & 0.299 \\
\hline Trouble from alcohol use & 25.2 & 22.3 & 12.6 & -12.6 & $<0.001$ \\
\hline \multicolumn{6}{|l|}{ Injury and violence } \\
\hline Any serious injury & 42.2 & 42.4 & 38.4 & -3.8 & 0.157 \\
\hline Bullied & 26.6 & 24.3 & 29.7 & +3.1 & 0.094 \\
\hline In physical fight & 43.8 & 44.7 & 33.3 & -10.5 & $<0.001$ \\
\hline Physically attacked & 30.2 & 30.4 & 19.3 & -10.9 & $<0.001$ \\
\hline \multicolumn{6}{|l|}{ Poor mental health } \\
\hline Having no close friends & 4.5 & 6.6 & 5.9 & +1.4 & 0.073 \\
\hline Loneliness & 7.5 & 5.8 & 10.1 & +2.6 & 0.053 \\
\hline Worry-induced sleep disturbance & 7.6 & 5.7 & 8.1 & +0.5 & 0.362 \\
\hline Suicidal ideation & 14.0 & 11.7 & 13.8 & -0.2 & 0.773 \\
\hline Suicide plan & 11.2 & 11.9 & 11.0 & -0.2 & 0.960 \\
\hline \multicolumn{6}{|l|}{ Sexual behaviour } \\
\hline Ever sex & 44.4 & 48.2 & 48.2 & +3.8 & 0.298 \\
\hline Multiple sexual partners & 34.8 & 25.9 & 28.4 & -6.4 & 0.036 \\
\hline Non-condom use & 10.2 & 8.9 & 7.7 & -2.5 & 0.055 \\
\hline \multicolumn{6}{|l|}{ Protective factors } \\
\hline School attendance & 60.0 & 65.9 & 68.3 & +8.3 & 0.002 \\
\hline Peer support (mostly/always) & 50.1 & 47.1 & 46.8 & -3.3 & 0.316 \\
\hline Parents/guardians supervision (mostly/always) & 37.7 & 32.4 & 30.4 & -7.3 & 0.005 \\
\hline Parents/guardians connectedness (mostly/always) & 52.6 & 46.8 & 42.9 & -9.7 & $<0.001$ \\
\hline Parents/guardians bonding (mostly/always) & 53.9 & 49.6 & 53.2 & -0.7 & 0.837 \\
\hline
\end{tabular}

${ }^{\mathrm{a}}$ Difference between 2007 and 2018; ${ }^{\mathrm{b}}$ Adjusted for age and socioeconomic status (food insecurity)

regarding tobacco use, and enforcing manufacturers to include messages warning of the harmful effects of cigarette smoking on health." $[24,25]$. However, of concern is that the prevalence of other tobacco use, significantly increased among girls from 2007 to 2018. Current alcohol decreased among boys, trouble from alcohol use decreased among both boys and girls, and lifetime drunkenness increased among girls. Current alcohol use is high in both sexes (52\% among boys and 56\% among girls) and is among adolescents often associated with negative health outcomes, such as interpersonal violence [13]. Public health interventions may be indicated to reduce alcohol use among adolescents in Argentina [13]. Although some national policies and interventions are 
Table 4 Health risk behaviours among female adolescents in 2007, 2012 and 2018 in Argentina

\begin{tabular}{|c|c|c|c|c|c|}
\hline \multirow[t]{2}{*}{ Outcome variable } & \multirow{2}{*}{$\begin{array}{l}2007 \\
\%\end{array}$} & \multirow{2}{*}{$\begin{array}{l}2012 \\
\%\end{array}$} & \multirow{2}{*}{$\begin{array}{l}2018 \\
\%\end{array}$} & \multirow[t]{2}{*}{ Difference $^{a}$} & \multirow[t]{2}{*}{$p$-for trend ${ }^{b}$} \\
\hline & & & & & \\
\hline \multicolumn{6}{|l|}{ Body weight and dietary behaviour } \\
\hline Overweight/obesity & 12.4 & 21.0 & 25.9 & +13.5 & $<0.001$ \\
\hline Obesity & 1.9 & 3.4 & 5.2 & +3.3 & $<0.001$ \\
\hline Fruits $<2$ times/day & 65.4 & 59.1 & 78.6 & +13.2 & $<0.001$ \\
\hline Vegetable <3 times/day & 90.8 & 86.4 & 89.2 & -1.6 & 0.427 \\
\hline Went hungry (mostly/always) & 1.8 & 3.1 & 1.7 & -0.1 & 0.483 \\
\hline \multicolumn{6}{|l|}{ Physical activity and sedentary behaviour } \\
\hline Physical inactivity & 92.2 & 87.8 & 87.1 & -5.1 & $<0.001$ \\
\hline Leisure-time sedentary behaviour & 51.0 & 52.8 & 57.7 & +6.7 & 0.036 \\
\hline 0 days walk or bike to school & 26.2 & 32.1 & 34.0 & +7.8 & 0.046 \\
\hline \multicolumn{6}{|l|}{ Substance use } \\
\hline Parental tobacco use & 38.6 & 35.8 & 35.2 & -3.4 & 0.114 \\
\hline Current cigarette use & 26.9 & 21.3 & 20.6 & -6.3 & 0.005 \\
\hline Current other tobacco use & 4.3 & 5.8 & 8.0 & +3.7 & 0.006 \\
\hline Passive smoking & 78.5 & 76.7 & 68.4 & -9.9 & $<0.001$ \\
\hline Current alcohol use & 53.2 & 51.3 & 55.7 & +2.5 & 0.290 \\
\hline Lifetime drunk & 31.2 & 29.5 & 38.8 & +7.6 & $<0.001$ \\
\hline Trouble from alcohol use & 20.8 & 21.8 & 13.3 & -8.5 & $<0.001$ \\
\hline \multicolumn{6}{|l|}{ Injury and violence } \\
\hline Any serious injury & 26.2 & 25.3 & 28.4 & +2.2 & 0.171 \\
\hline Bullied & 23.6 & 23.5 & 34.9 & +11.3 & $<0.001$ \\
\hline In physical fight & 19.6 & 24.1 & 16.5 & -3.1 & 0.075 \\
\hline Physically attacked & 19.2 & 19.8 & 15.9 & -3.3 & 0.042 \\
\hline \multicolumn{6}{|l|}{ Poor mental health } \\
\hline Having no close friends & 4.0 & 4.7 & 5.3 & +1.3 & 0.043 \\
\hline Loneliness & 12.8 & 13.1 & 23.1 & +10.3 & $<0.001$ \\
\hline Worry-induced sleep disturbance & 13.7 & 11.9 & 18.0 & +4.3 & $<0.001$ \\
\hline Suicidal ideation & 19.8 & 22.2 & 28.6 & +8.8 & $<0.001$ \\
\hline Suicide plan & 15.8 & 19.6 & 22.6 & +6.8 & $<0.001$ \\
\hline \multicolumn{6}{|l|}{ Sexual behaviour } \\
\hline Ever sex & 24.4 & 35.2 & 36.4 & +12.0 & $<0.001$ \\
\hline Multiple sexual partners & 13.6 & 14.9 & 16.9 & +3.3 & 0.210 \\
\hline Non-condom use & 7.0 & 7.8 & 8.4 & +1.4 & 0.532 \\
\hline \multicolumn{6}{|l|}{ Protective factors } \\
\hline School attendance & 65.7 & 69.3 & 72.3 & +6.6 & 0.016 \\
\hline Peer support (mostly/always) & 57.8 & 53.8 & 44.5 & -13.3 & $<0.001$ \\
\hline Parents/guardians supervision (mostly/always) & 37.0 & 28.6 & 26.6 & -10.4 & $<0.001$ \\
\hline Parents/guardians connectedness (mostly/always) & 54.9 & 49.7 & 40.0 & -14.9 & $<0.001$ \\
\hline Parents/guardians bonding (mostly/always) & 59.2 & 58.0 & 56.9 & +0.7 & 0.116 \\
\hline
\end{tabular}

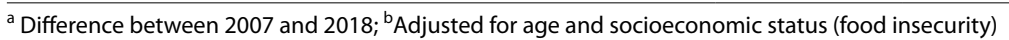

in place for alcohol use in Argentina, such as legal minimum age for on or off premise sales of alcoholic beverages (18 years), and legally binding regulations on alcohol advertising, health warning labels on alcohol advertisements, there is no written national alcohol policy, no legally binding regulations on alcohol sponsorship, and no restrictions for on-/off-premises sales of alcoholic beverages [26].

Overweight/obesity and obesity, sedentary behaviour, not walking/biking to school (particularly among girls), and inadequate fruit consumption increased from 2007 to 2018, which may be attributed to a nutritional 
transition (to increased intake of processed foods, sugarsweetened soft drinks or juices, and reduction of total fruit consumption) in Argentina [27]. The increase in sedentary behaviour may be attributed to an increased internet and mobile devices use among adolescents in Argentina [28]. Among girls, the prevalence of physical inactivity decreased, and was among both boys and girls like global rates (85\%) [29]. However, the prevalence of sedentary behaviour was much higher than global estimates among adolescents (30\%) [29]. It is possible that not walking/biking to school increased among girls because of lower parental supervision and peer support [30], as found in this study. The extent of food insecurity was below $2.4 \%$ in 2018 , decreased among boys and remained unchanged among girls. The federal in-school feeding programme may have had a positive impact to reduce food insecurity [31].

In line with some previous trend studies [18, 32-34], this study showed that physically assaulted and involvement in physical fighting declined over time. Perhaps, one factor contributing to the decline in interpersonal violence, is the decline of alcohol use among boys in this study [13]. In addition, we found an increase in school attendance in our study, which may also have contributed to the decline of interpersonal violence. Compared to boys, bullying victimisation increased significantly among girls. It is possible that the decline in peer support among girls in this study contributed to an increase in being bullied among girls. The prevalence of bullying victimization in this study was higher in girls than in boys, which has also been reported in a different study in Argentina, Uruguay, and Brazil [35]. The overall participation in physical fighting (30.0\%) and bullying victimisation (27.3\%) in this study were lower than among adolescents from Bolivia, Costa Rica, Honduras, Peru, and Uruguay (33.2\% had been involved in physical fighting $37.8 \%$ were bullied) [15].

Regarding sexual behaviour, among boys, sexual risk behaviour (multiple sexual partners and non-condom use) decreased over time, and girls ever sexual intercourse increased over time. The since 2006 a national programme on comprehensive sexual education curriculum has been integrated across school levels [36], which may have contributed to low sexual risk behaviour. Compared to studies among adolescents in South America, the overall prevalence of non-condom use $(8.3 \%$ overall and $22.9 \%$ among sexually active) was similar to Bolivia, Costa Rica, Honduras, Peru, and Uruguay (6.7\%) [15] and lower than in Brazil (30.8\% among sexually active) [16], and the overall prevalence of multiple sexual partners $(21.9 \%$ overall and $53.2 \%$ among sexually active) in this study was lower than in Brazil ( $>63 \%$ among sexually active) in Brazil [16].
Among boys, all mental health indicators remained unchanged, while among girls all five mental health indicators (suicide plan, loneliness, suicidal ideation, no close friends, and worry-induced sleep disturbance) significantly increased from 2007 to 2018. In response to this a gender-responsive health for suicide prevention programme through the establishment of school-based health advisory services has recently been implemented and is being roll-out in Argentina [37]. The overall prevalence of suicidal ideation (18.4\%) in this study was similar to the study among adolescents in five Latin American countries (19.5\%) [15].

Regarding protective aspects, school attendance increased among both boys and girls, while peer support significantly decreased among girls but not among boys. Parental supervision and connectedness significantly decreased among both boys and girls over time in this study. This decline in parental support may be related to recent changes in family transformations in Argentina, including "increases in the age at marriage, marital dissolution, nonmarital births, and cohabitation, and with women increasingly contributing to the economic support of their families." [38]. It is possible that the decline of parental supervision and connectedness contributed to poorer mental health, in particular among girls in this study. Overall, the prevalence of parental support (parental supervision $31.2 \%$, parental connectedness $47.1 \%$ and parental bonding 54.9\%) in this study was lower in terms parental supervision (38.2\%) but higher regarding parental connectedness (32.9\%) and parental bonding (40.2\%) than among adolescents in five Caribbean countries [17].

Study findings highlight a wide range of health risk behaviours that can be targeted in school health promotion activities among in Argentina. Comprehensive Protection of the Rights of Boys, Girls and Adolescents, PROSANE is developed as an "Integrated Care Policy for children and adolescents". 'PROSANE is part of the Primary Health Care strategy strengthening the link between the school and the health centre makes it possible to identify issues that require promotional actions in schools. PROSANE promotes and develops health promotion actions in conjunction with teachers, managers, and families, promoting learning and integral human development, improving the quality of life and the collective well-being of children and adolescents and other members of the community [39].

\section{Study limitations}

"Secondary education net-enrolment ratio" was $85.9 \%$ in Argentina in 2012 and $90.7 \%$ in 2018 [40], which implies that some adolescents not attending school were not included in this study in Argentina. Some GSHS study variables, such as oral and hand hygiene, 
soft drink and fast-food consumption, were not included in this paper, since they were only assessed in one or two waves of the Argentina GSHS. The study design was cross-sectional, which precludes from causal inferences. The GSHS collected anonymously data by self-report that could have contributed to some bias but may nevertheless have reported valid data, in particular on sensitive issues [41].

\section{Conclusions}

Nine health risk behaviours (current cigarette use, passive smoking, trouble from alcohol use, physically attacked, experience of hunger, parental tobacco use, current alcohol use, and involvement in physical fighting) among boys and five health risk behaviours (current cigarette use, passive smoking, trouble from alcohol use, physically attacked, and inadequate physical inactivity) among girls decreased, and four health risk behaviours (overweight/obesity, obesity, leisure-time sedentary behaviour and insufficient fruit intake) among boys and 14 health compromising behaviours (overweight/ obesity, obesity, leisure-time sedentary behaviour and insufficient fruit intake, not walking/biking to school, current other tobacco use, bullying victimisation, lifetime drunkenness, having no close friends, loneliness, worry-induced sleep disturbance, suicidal ideation, suicide plan, and ever sexual intercourse) among girls increased over a period of 11 years. School health programmes for adolescents should be strengthened in Argentina.

\section{Acknowledgement \\ The data source, the World Health Organization NCD Microdata Repository (URL: https://extranet.who.int/ncdsmicrodata/index.php/catalog), is hereby acknowledged.}

\section{Authors' contributions}

All authors fulfil the criteria for authorship. KP and SP conceived and designed the research, performed statistical analysis, drafted the manuscript, and made critical revisions of the manuscript for key intellectual content. All authors read and approved the final version of the manuscript and have agreed to the authorship and order of authorship for this manuscript.

\section{Funding}

The analysis received no funding

\section{Availability of data and materials}

The datasets generated during and/or analysed during the current study are available in the World Health Organization NCD Microdata Repository, https:// extranet.who.int/ncdsmicrodata/index.php/catalog/Public access to this database is open.

\section{Declarations}

All methods were carried out in accordance with relevant guidelines and regulations and have been performed in accordance with the Declaratio $\mathrm{n}$ of Helsinki.Ethics approval and consent to participate

The study was granted ethics approval by a national ethics committee and written informed consent was obtained from the participants or their guardians before the survey.
Consent for publication

Not applicable

\section{Competing interests}

The authors declare that they have no competing interests.

\section{Author details}

${ }^{1}$ Department of Psychology, College of Medical and Health Science, Asia University, Taichung, Taiwan. ${ }^{2}$ Department of Research Administration and Development, University of Limpopo, Turfloop, South Africa. ${ }^{3}$ ASEAN Institute for Health Development, Mahidol University, Salaya, Phutthamonthon, Nakhon Pathom, Thailand.

Received: 11 August 2021 Accepted: 22 September 2021

Published online: 21 October 2021

\section{References}

1. Pan American Health Organization. Noncommunicable diseases in the Region of the Americas: facts and figures. Washington, D.C.: PAHO; 2019

2. Linetzky B, De Maio F, Ferrante D, Konfino J, Boissonnet C. Sex-stratified socio-economic gradients in physical inactivity, obesity, and diabetes: evidence of short-term changes in Argentina. Int J Public Health. 2013;58(2):277-84. https://doi.org/10.1007/s00038-012-0371-z.

3. Olivares DE, Chambi FR, Chañi EM, Craig WJ, Pacheco SO, Pacheco FJ. Risk Factors for Chronic Diseases and Multimorbidity in a Primary Care Context of Central Argentina: A Web-Based Interactive and Cross-Sectional Study. Int J Environ Res Public Health. 2017;14(3):251. https://doi.org/10. 3390/ijerph14030251.

4. Bardach AE, Elorriaga N, Alcaraz AO, Rubinstein AL, Tavella JM. Community-based cardiovascular health promotion in Argentina. A systematic review. Health Promot Int. 2018;33(4):695-712. https://doi.org/10.1093/ heapro/daw107.

5. World Health Organization (WHO). Global school-based student health survey (GSHS), 2020. URL: https://www.who.int/ncds/surveillance/gshs/ en/ (accessed 10 Apr 2020)

6. Aguilar-Farias N, Martino-Fuentealba P, Carcamo-Oyarzun J, CortinezO'Ryan A, Cristi-Montero C, Von Oetinger A, et al. A regional vision of physical activity, sedentary behaviour and physical education in adolescents from Latin America and the Caribbean: results from 26 countries. Int J Epidemiol. 2018:47(3):976-86. https://doi.org/10.1093/ije/dyy033.

7. Beck NI, Arif I, Paumier MF, Jacobsen KH. Adolescent injuries in Argentina, Bolivia, Chile, and Uruguay: Results from the 2012-2013 Global Schoolbased Student Health Survey (GSHS). Injury. 2016;47(12):2642-9. https:// doi.org/10.1016/j.injury.2016.10.002

8. Resett S, Gamez-Guadix M. Traditional bullying and cyberbullying: Differences in emotional problems, and personality. Are cyberbullies more Machiavellians? J Adolesc. 2017;61:113-6. https://doi.org/10.1016/j.adole scence.2017.09.013.

9. Koyanagi A, Oh H, Carvalho AF, Smith L, Haro JM, Vancampfort D, Stubbs B, DeVylder JE. Bullying Victimization and Suicide Attempt Among Adolescents Aged 12-15 Years From 48 Countries. J Am Acad Child Adolesc Psychiatry. 2019 Sep;58(9):907-918.e4. doi: https://doi.org/10.1016/j.jaac. 2018.10.018.

10. Ferrante D, Linetzky B, Ponce M, Goldberg L, Konfino J, Laspiur S. Prevalence of overweight, obesity, physical activity and tobacco use in Argentine youth: Global School-Based Student Health Survey and Global Youth Tobacco Survey, 2007-2012. Arch Argent Pediatr. 2014;112(6):496-503. https://doi.org/10.5546/aap.2014.496.

11. Elia C, Karamanos A, Dregan A, O'Keeffe M, Wolfe I, Sandall J, et al. Association of macro-level determinants with adolescent overweight and suicidal ideation with planning: A cross-sectional study of 21 Latin American and Caribbean Countries. PLoS Med. 2020;17(12):e1003443. https://doi.org/10.1371/journal.pmed.1003443.

12. Sauter SR, Kim LP, Jacobsen KH. Loneliness and friendlessness among adolescents in 25 countries in Latin America and the Caribbean. Child Adolesc Ment Health. 2020;25(1):21-7. https://doi.org/10.1111/camh. 12358. 
13. Pierobon M, Barak M, Hazrati S, Jacobsen $\mathrm{KH}$. Alcohol consumption and violence among Argentine adolescents. J Pediatr (Rio J). 2013;89(1):1007. https://doi.org/10.1016/j.jped.2013.02.015.

14. Peltzer K, Pengpid S. Cannabis and amphetamine use and socio-ecological (proximal and distal) factors among school-going adolescents in four countries in the Caribbean and four countries in South America. Int J Adolesc Med Health. 2019;11:33(1). https://doi.org/10.1515/ ijamh-2018-0030.

15. Romo ML, Kelvin EA. Impact of bullying victimization on suicide and negative health behaviors among adolescents in Latin America. Rev Panam Salud Publica. 2016:40(5):347-55.

16. Noll M, Noll PRES, Tiggemann CL, Custodio DC, Silveira EA. Health-risk behavior differences between boarding and non-resident students: Brazilian adolescent National School Health Survey. Arch Public Health. 2020;78:8. https://doi.org/10.1186/s13690-020-0392-7.

17. Pengpid S, Peltzer K. Parental involvement and mental health among school-going adolescents in five Caribbean countries. J Psychol Afr. 2018;28(5):394-9. https://doi.org/10.1080/14330237.2018.1501916.

18. Peltzer K, Pengpid S. Health risk behaviour among in-school adolescents in the Philippines: trends between 2003, 2007 and 2011, a cross-sectional study. Int J Environ Res Public Health. 2015;13(1):73. https://doi.org/10. 3390/ijerph1301007317.

19. Pengpid S, Peltzer K. Trends of dietary behaviour, physical activity, interpersonal violence and hand hygiene behaviour among school-going adolescents in Oman: cross-sectional national surveys from 2005, 2010 and 2015. Vulnerable Child Youth Stud. 2019. https://doi.org/10.1080/ 17450128.2019 .1710632$.

20. Pengpid S, Peltzer K. Trends of 20 Health Risk Behaviours Among Adolescents in Morocco: Results of Three National Cross-Sectional School Surveys of 2006, 2010 and 2016. Int J Gen Med. 2021;14:1611-9. https:// doi.org/10.2147/IJGM.S283137.

21. Centers for Disease Control and Prevention (CDC). State indicator report on fruits and vegetables. Available online: http://www.cdc.gov/nutrition/ downloads/state-indicator-reportfruits- vegetables-2013.pdf (Accessed 10 Oct 2020).

22. World Health Organization (WHO). Physical activity fact sheet. 2017. Available from: http://www.who.int/mediacentre/factsheets/fs385/en/ . Accessed 10 Apr 2020.

23. Guthold R, Cowan MJ, Autenrieth CS, Kann L, Riley LM. Physical activity and sedentary behavior among schoolchildren: a 34-country comparison. J Pediatr. 2010;157:43-49.e1. doi: https://doi.org/10.1016/j.jpeds. 2010.01.019

24. Ministerio de Justicia y Derechos Humanos (Presidencia de la Nación Argentina). Ley 26.687. Regulación de la publicidad, promoción y consumo de los productos elaborados con tabaco. 2011. URL: http:// servicios.infoleg.gob.ar/infoleglnternet/anexos/180000-184999/183207/ norma.html. (Accessed 20 May 2021).

25. Santero M, Melendi S, Hernández-Vásquez A, Irazola V. Socio-economic inequalities in smoking prevalence and involuntary exposure to tobacco smoke in Argentina: Analysis of three cross-sectional nationally representative surveys in 2005, 2009 and 2013. PLoS One. 2019;14(6):e0217845. https://doi.org/10.1371/journal.pone.0217845.

26. World Health Organization (WHO). Argentina, 2018. URL: https://www. who.int/publications/m/item/alcohol-arg-2019 accessed (5 Aug 2021)

27. Pou SA, Tumas N, Aballay LR. Nutrition Transition and Obesity Trends in Argentina Within the Latin American Context. In: Faintuch J, Faintuch S, editors. Obesity and Diabetes. Cham: Springer; 2020. https://doi.org/10. 1007/978-3-030-53370-0_2.

28. UNICEF. Global Kids Online Argentina: Research study on the perceptions and habits of children and adolescents on the use of technologies, the internet and social media, 2016. URL: chrome-extension://efaidnbmnnnibpcajpcglclefindmkaj/viewer.html?pdfurl=http\%3A\%2F\%2Fe prints.Ise.ac.uk\%2F71284\%2F1\%2FCountry-report_Argentina_28-Oct. pdf\&clen $=1785252$ (accessed 5 Aug 2021)

29. Uddin R, Lee EY, Khan SR, Tremblay MS, Khan A. Clustering of lifestyle risk factors for non-communicable diseases in 304,779 adolescents from 89 countries: a global perspective. Prev Med. 2020;131:105955. https://doi. org/10.1016/j.ypmed.2019.105955.

30. Khan A, Uddin R. Parental and peer supports are associated with an active lifestyle of adolescents: evidence from a population-based survey. Public Health. 2020;188:1-3. https://doi.org/10.1016/j.puhe.2020.08.024.

31. Adrogue C, Orlicki ME. Do in-school feeding programs have an impact on academic performance and dropouts? The case of public schools in Argentina. Education Policy Analysis Archives. 2013;21(50), from http:// epaa.asu.edu/ojs/article/view/1162

32. Pengpid S, Peltzer K. Trends of alcohol use, dietary behaviour, interpersonal violence, mental health, oral and hand hygiene behaviour among adolescents in Lebanon: cross-sectional national school surveys from 2005, 2011 and 2017. Int J Environ Res Public Health. 2020;17(19):7096. https://doi.org/10.3390/ijerph17197096.

33. Pengpid S, Peltzer K. Trends in the prevalence of twenty health indicators among adolescents in United Arab Emirates: cross-sectional national school surveys from 2005, 2010 and 2016. BMC Pediatr. 2020;20(1):357. https://doi.org/10.1186/s12887-020-02252-0.

34. Finkelhor D, Turner HA, Shattuck A, Hamby SL. Prevalence of childhood exposure to violence, crime, and abuse: results from the National Survey of Children's Exposure to Violence. JAMA Pediatr. 2015;169(8):746-54. https://doi.org/10.1001/jamapediatrics.2015.0676.

35. Chávez C, Cebotari V, Benítez MJ, Richardson D, Fen Hiu C, Zapata J. School-Related Violence in Latin America and the Caribbean: Building an Evidence Base for Stronger Schools. In: Innocenti Working Paper 2021-02. Florence: UNICEF Office of Research - Innocenti; 2021.

36. Banegas DL. Comprehensive sexual education and English language teaching: an endeavour from southern Argentina, Innovation in Language Learning and Teaching. 2021;15:3: 210-217, DOI: https://doi.org/10. 1080/17501229.2020.1737704

37. UNICEF. Adolescent Mental Health Matters: A Landscape Analysis of Unicef's Response and Agenda for Action, 2020. URL: chrome-extension://efaidnbmnnnibpcajpcglclefindmkaj/viewer. html?pdfurl=https\%3A\%2F\%2Fwww.unicef.org\%2Fmedia\%2F82926 \%2Ffile\%2FAdolescent-Mental-Health-Matters-Report-Final-July2020. pdf\&clen $=4189517 \&$ chunk $=$ true (accessed 7 Aug 2021).

38. Binstock G. Continuity and Change: The Family in Argentina, 2007. In: Jayakody R, Thornton A \& Axinn W (Eds.) International Family Change: Ideational perspectives (pp.). New York: Routledge.

39. Pigeon WR, Pinquart M, Conner K. Meta-analysis of sleep disturbance and suicidal thoughts and behaviors. J Clin Psychiatry. 2012;73(9):e1160-7. https://doi.org/10.4088/JCP.11r07586.

40. Ministerio de Salud. Programa Nacional de Salud Escolar, 2020. URL: https://www.argentina.gob.ar/salud/dinamia/saludescolar (accessed 5 Aug 2021).

41. UNESCO. Participation in education, Argentina, 2019. URL: http://uis. unesco.org/en/country/ar (accessed 2 Apr 2021).

\section{Publisher's Note}

Springer Nature remains neutral with regard to jurisdictional claims in published maps and institutional affiliations. 